\title{
CULTURA EMPRESARIAL E REESTRUTURAÇÃO PRODUTIVA NA INDÚSTRIA BRASILEIRA: O CASO DA LUPO S/A
}

\author{
LORENZO, Helena Carvalho De
}

Docente e pesquisadora do Programa de Mestrado em Desenvolvimento Regional e Meio Ambiente do Centro Universitário de Araraquara - Uniara. E-mail: hclorenzo@uniara.com.br

CAÍRES, Ângela Cristina Ribeiro

Faculdades Integradas-Jaú/SP e Faculdades do Interior Paulista-Barra Bonita/SP. Doutora em Sociologia pela FCL/Unesp-Araraquara/SP. E-mail: angelacaires@uol.com.br

\section{Resumo}

Fundada em 1921, a empresa atualmente denominada Lupo S/A é das mais antigas das indústrias do setortêxtil e confecções da Brasil. Neste artigo se busca traçar as linhas gerais da trajetória da empresa familiar, hoje voltada para a produção de meias, lingeries e artigos esportivos. O foco do artigo está na análise de algumas estratégias utilizadas pela empresa ao longo de seu processo de formação e desenvolvimento e, em particular, a forma como essas estratégias possibilitaram a reestruturação produtiva associada à superação de forte crise iniciada no final dos anos 80 e começo dos 90 , possibilitando sua consolidação recente na indústria de confecções. A hipótese norteadora do estudo é de que a forte cultura organizacional que se foi formando e se consolidando desde sua fundação, restabelecida na gestão mais recente, foi o fator responsável pelos avanços capazes de gerar um ambiente de inovação tanto em produtos quanto em processos e gestão. A reflexão teórica selecionada para subsidiar a construção cognitiva do estudo da empresa está apoiada na abordagem histórica sobre o desenvolvimento da indústria têxtil no Brasil e em estudos sobre importância da ação do empreendedor, no papel da cultura organizacional e da inovação para a escolha das estratégias em empresas. A pesquisa realizada envolveu a análise de documentos e dados da empresa, além de entrevistas com diretores e funcionários. Os resultados mostram um modelo tradicional da empresa, mas também a presença de uma dinâmica empresarial muito avançada. O mundo moderno - conhecido como modelo industrial fordista - já podia ser percebido na empresa quando este padrão de produção ainda não estava claramente definido na indústria brasileira.Atualmente, a empresa enfrenta o desafio da globalização e da competição aberta no mercado internacional, que traz a concorrência das maiores e melhores empresas globalizadas.

Palavras-Chave: História de empresa; Cultura empresarial; Reestruturação produtiva.

\begin{abstract}
Founded in 1921, the company currently known as Lupo S/A is one of the most ancient textile and clothing industries in Brazil. In this article we aim to describe the general lines of the trajectory of this family company, currently producing socks, nightwear and sports articles. The focus of this paper is on the analysis of some strategies used by the company along its formation and development process, and, particularly, the way these strategies made possible the productive restructuring associated to the overcoming of the strong crisis which began in the end of the 80 's and early 90 's, contributing to its recent consolidation in the clothing industry. The leading hypothesis of the study is that pioneering connected to a strong organizational culture that has been formed and constructed since its foundation and that was reestablished in a more recent management were the factors which were responsible for the advances able to generate an innovation environment in products as well as in processes and management. The theoretical reflection selected to subsidize the cognitive construction of the study of the company is based on the historical approach of the development of the textile industry in Brazil and in studies about the importance of the action of the entrepreneur, in the role of the organizational culture and
\end{abstract}


of innovation to choose strategies in companies. The research involved the analysis of documents and data of the company, as well as interviews with directors and employees. The results show a traditional company model, but also show the presence of a very advanced entrepreneurial dynamic. Modern world - known as a fordist industrial model - could already be noticed in the company when this production pattern was not clearly defined yet in the Brazilian industry. Nowadays, the company faces the challenge of globalization and the open competition in the international market which brings the rivalry of the greatest and best globalized companies.

KEYwORDs: Company history; Entrepreneurial culture; Productive restructuration.

\section{INTRODUÇÃo}

Ao longo de seus 89 anos de existência, a empresa atualmente denominada Lupo S/A, que começou como uma pequena unidade familiar para produzir meias masculinas, passou por profundas transformações tanto na produção e comercialização de seus produtos, quanto em sua estrutura administrativa, organizacional e tecnológica. A empresa vivenciou todas as fases que, de um modo geral, caracterizaram a economia brasileira e a evolução da indústria têxtil e de confecções no Brasil. Nasceu no contexto da economia agroexportadora, e rapidamente deixou de ser uma pequena empresa local, tornando-se uma grande empresa de porte nacional. Após a crise da economia agroexportadora, teve forte crescimento associado ao atendimento da demanda interna, da mesma forma que outras indústrias têxteis no Brasil. Diversas empresas hoje líderes no mercado também surgiram nesses períodos iniciais da indústria têxtil no Brasil: em 1883, a Companhia Cedro e Cachoeira; em1906, Cia. Industrial Belo Horizonte; em 1914, Delmiro Gouveia (hoje, Fábrica da Pedra); em 1921 a Lupo; em 1929 a Santista Têxtil; e, em 1946, a Vicunha Têxtil.

A trajetória da indústria têxtil e de vestuário no Brasil refletiu-se fortemente nas empresas do setor. A partir dos anos 1970, quando a indústria brasileira ganha maior diversificação e dinamismo e a economia brasileira passa a apresentar uma estrutura produtiva mais completa, o setor têxtil perde importância relativa, mas ainda apresenta forte dinamismo apoiado no crescimento econômico. Nos anos 1990, com a abertura comercial acelerada, a indústria têxtil e de confecções é um dos setores que mais sofrem com o aumento das importações. Muitas empresas fecharam e houve forte redução do emprego. Também nos anos 1990, o avanço da globalização e a imposição de forte processo de reestruturação produtiva e organizacional alteram o padrão de concorrência e provocam outras mudanças na produção e comercialização do setor, e trouxeram como consequência fortes mudanças nos preços e nas condições de produção com impactos nas empresas.

Neste artigo se busca traçar as linhas gerais da trajetória da Lupo S/A, até o presente ainda uma empresa familiar, hoje voltada para a produção de meias e lingeries e produtos esportivos. $\mathrm{O}$ foco do artigo está na análise de algumas estratégias utilizadas pela empresa ao longo de seu processo de crescimento e, em particular, a forma como essas estratégias possibilitaram o processo de superação de forte crise iniciada no final dos anos 1980 e começo dos 1990, e permitiram sua consolidação recente como grande potência da indústria de confecções.

A hipótese norteadora do estudo é de que os fortes traços da cultura empresarial que se foram formando e se consolidando desde a fundação, e restabelecidos em gestão mais recente, foram os fatores responsáveis pelos avanços capazes de gerar um ambiente de inovação tanto em produtos quanto em processos e gestão.

A reflexão teórica selecionada para subsidiar a construção cognitiva para o estudo da empresa está apoiada em dupla abordagem. Em primeiro lugar, tomou-se como referência a abordagem histórica sobre o desenvolvimento da indústria têxtil no Brasil para compreender o desenvolvimento da empresa. Nesse sentido os dados foram organizados por períodos, buscando compatibilizar a história da empresa às 
principais fases da indústria brasileira. Em segundo lugar, a análise se apoia em estudos sobre o papel da cultura organizacional na escolha das estratégias em empresas e na importância da ação do empreendedor orientada pelo conhecimento, que facilita as adaptações e inovações em um quadro de aproveitamento das oportunidades.

Do ponto de vista metodológico, o estudo pode ser considerado exploratório e qualitativo. A pesquisa realizada envolveu a análise de documentos e dados da empresa, além de entrevistas com diretores e funcionários. As informações obtidas foram analisadas à luz de conceitos extraídos das abordagens mencionadas. A compreensão do desenvolvimento produtivo da empresa ocorrido ao longo do tempo e organizado por períodos pautou-se na análise das seguintes categorias de análise: produtos e produção, inovação e tecnologia, integração vertical, relações de trabalho, comercialização e distribuição. Essas categorias, sugeridas pela literatura sobre cultura empresarial e sobre a história e evolução da indústria têxtil no Brasil, e apresentadas na seção de referências teóricas, foram decisivas para a organização dos dados.

Os padrões culturais da empresa foram gerados desde a primeira fase pelo seu fundador, Henrique Lupo, e reproduzidos pelos seus filhos e netos nas gestões posteriores. Foram também compartilhados pelos primeiros líderes e demais trabalhadores que fizeram da Lupo uma empresa de projeção nacional, marcada pela competência, mas também pela tradição e certa dose de conservadorismo. Tais valores foram também responsáveis pela consolidação de uma cultura forte, ao mesmo tempo em que contribuíram para a construção da identidade empresarial. Todavia, não impediram que a empresa enfrentasse graves crises de naturezas diversas, mas foram importantes para sua superação.

O presente artigo está organizado em nove seções, iniciadas por esta introdução. Na 2. ${ }^{a}$ seção apresentamse a contribuição dos estudos sobre cultura empresarial para a compreensão das estratégias empresariais. $\mathrm{Na}$ 3. ${ }^{a}$ seção estuda-se o papel desempenhado pelo fundador na condução da empresa desde sua fundação até o seu falecimento, em agosto de 1963. Esse é um tempo decisivo na história da empresa. Momento em que, como já mencionado, tem início a construção da sua cultura. Nas seções seguintes $\left(4 .^{a},{ }^{a} .^{a}, 6 .^{a}\right.$ e $\left.7 .{ }^{a}\right)$ analisam-se as principais características da empresa por períodos, buscando em cada um deles os principais traços da evolução da empresa a partir das categorias anteriormente citadas: produtos e produção, preocupação com a tecnologia e sentido da inovação, a introdução da integração vertical na produção, as especificidades na forma de conduzir as relações de trabalho, as formas de comercialização e distribuição da produção; na $8 .^{a}$ seção estuda-se a força das relações familiares nas tomadas de decisões, nas estratégias e contribuições da empresa para a vida empresarial frente às exigências do mundo globalizado e da competição em mercado aberto à concorrência internacional, quando terá de enfrentar as melhores e maiores multinacionais.

\section{A Contribuição dos estudos sobre CUltura ORganizaCIONAL PARA A COMPREENSÃo DAS ESTRATÉGIAS EMPRESARIAIS}

O tema cultura organizacional tem sido amplamente utilizado nos estudos administrativos para a compreensão da trajetória de empresas. A contribuição desses estudos está relacionada ao fato de que, para alguns autores, as escolhas, as decisões e a definição das estratégias empresariais se fundamentam, em grande parte, na importância da cultura organizacional, e esclarecem:

A cultura organizacional é o conjunto de hábitos e crenças estabelecidos através de normas, valores, atitudes, e expectativas compartilhadas por todos os membros da organização. Ela referese ao sistema de significados compartilhados por todos os membros e que distingue uma organização das demais. Constitui o modo institucionalizado de pensar e agir que existe em uma organização. A essência da cultura de uma empresa é expressa pela maneira como ela faz seus negócios, a maneira como ela trata seus 
clientes e funcionários, o grau de autonomia e liberdade que existe em suas unidades ou escritórios e o grau de lealdade expresso por seus funcionários com relação à empresa. A cultura organizacional reflete as percepções dos dirigentes e funcionários da organização e reflete a mentalidade que predomina na organização (CHIAVENATO, 1999, pp.138/139).

A cultura organizacionalé ainda:

...um padrão de assuntos básicos compartilhados que um grupo aprendeu como maneira de resolver seus problemas de adaptação externa e integração interna, e que funciona bem a ponto de ser considerado válido e desejável para ser transmitido aos novos membros como a maneira correta de perceber, pensar e sentir em relação àqueles problemas. (SCHEIN, 1992 apud CHIAVENATO, 1999, p. 139).

Para Schein, assim como para outros estudiosos que vêm se ocupando deste tema, "o conjunto de pessoas que formam a organização é responsável pela formação da cultura, pela criação do conjunto de pressupostos básicos e por sua transformação." Entretanto, este mesmo autor, como destaca Fleury (1991, p. 249):

....atribui importância especial ao papel dos fundadores da organização no processo de moldagem de seus padrões culturais: os primeiros líderes ao desenvolverem formas próprias de equacionar os problemas da organização, acabam por imprimir a sua visão de mundo aos demais e também a sua visão das funções que esta deve desempenhar. Depois dos fundadores, os gerentes profissionais desempenham também este papel. Ou seja, apesar de todos os membros serem 'iguais' no processo de criação e modelagem da cultura, uns são mais iguais do que os outros; alguns produzem e interiorizam os padrões culturais de uma organização, outros nela são socializados e a internalizam.
A cultura organizacional construída ao longo do tempo, também como observa a autora mencionada, passa a impregnar todas as práticas, constituindo um complexo de representações mentais e um sistema coerente de significados que une todos os membros em torno dos mesmos objetivos e dos mesmos modos de agir. Ela serve de elo entre o presente e o passado e contribui para a permanência e a coesão da organização (grifo nosso).

Ainda em função de proposta deste estudo, cabe agora esclarecer o conceito de estratégia e o de estratégia empresarial como processos associados às decisões empresariais. Nesta direção e, de acordo com Porter (1997: 47), a definição de estratégia tem uma trajetória significativa para a compreensão do conceito aqui utilizado. Uma definição mais tradicional de estratégia estava relacionada à forma como recursos são alocados para se atingir determinado objetivo. Usada originalmente na área militar, esta palavra hoje é bastante usada na área de negócios. (...) A partir da área militar, a estratégia passou a fazer parte nos negócios, sendo o conjunto de objetivos da empresa e a forma de alcançá-los. E ainda mostra que o desenvolvimento de estratégias tem sido tradicionalmente abordado como um processo formal de planejamento, envolvendo, em geral, duas etapas: a primeira engloba a definição do negócio, bem como a explicitação da missão da organização e seus princípios. No entanto, em contexto do mundo globalizado e da reestruturação produtiva, a formulação e implementação de estratégias empresariais devem ser vistas como um processo de gestão visando à tomada de decisão em médio e longo prazos, envolvendo decisões relativas à definição de negócios (produtos, serviços, clientes-alvo, posicionamento, etc.) A inovação e o conhecimento são objetivos de desenvolvimento e fatores chave de sucesso.

Fleury (1991), que estudou casos relacionados com o tema, mostra que a estratégia tem a ver com fazer escolhas firmes em três dimensões: os clientes nos quais a empresa se concentrará e naqueles que conscientemente não visará os produtos que serão oferecidos ou não, e as atividades que serão executadas 
ou não. Para este professor, estratégia sempre tem a ver com escolhas, e a empresa não será bem-sucedida só por escolher uma posição estratégica diferente da dos concorrentes; portanto, a essência da estratégia está em escolher uma posição que a companhia defenderá como sua. Assim, uma posição estratégia é simplesmente a soma das respostas que uma empresa dá às seguintes questões: A quem deve visar como cliente? Quais produtos ou serviços devem ser oferecidos a eles? Como se pode fazer isso de maneira eficiente?

Entendendo, portanto, cultura organizacional como um conjunto de hábitos e crenças estabelecidos por meio de normas, valores, atitudes e expectativas, compartilhados por todos os membros da organização que explicam as escolhas estratégicas frente aos concorrentes, buscaram-se a compreensão da dinâmica empresarial da Lupo e suas escolhas estratégicas ao longo dos 85 anos de sua existência.

\section{A FUNDAÇÃO da EMPRESAS NO CONTEXTO DAS PRIMEIRAS INDÚSTRIAS TÊXTEIS NO Brasil E A CONSTRUÇÃO DAS PRIMEIRAS ESTRATÉGIAS}

A Fábrica de meias Lupo S/A, como registra a sua história, foi instalada em 1921 na casa de seu fundador com duas máquinas de meias da marca Banner ${ }^{3}$. À época da criação da Lupo, a atividade industrial era pouco relevante no Brasil. A indústria era uma atividade até então esparsa e pouco importante no país sendo que os imigrantes, principalmente os italianos, que aqui chegaram ao final do século XIX e início do século XX para trabalhar na lavoura cafeeira ou instalando pequenos negócios, tiveramuma forte participação no seu crescimento inicial. (SILVA, 1976)

As indústrias têxteis, que sempre tiveram lugar importante na economia brasileira, viram a sua efetiva implantação se efetuar somente a partir do final da primeira metade do século $\mathrm{XIX}^{4}$. Desde os anos finais do século XIX, a economia brasileira dependia da exportação de produtos agrícolas, e o café era a mais importante atividade produtiva da economia brasileira . Todas as demais atividades - bancos, comércio e, inclusive, industrial - foram se formando à sua volta, e a receita das exportações financiava a aquisição de bens de consumo. O café, portanto, gerava mercados para a indústria, sendo que o fortalecimento da agricultura era essencial para o seu crescimento. Podese dizer que havia mútua dependência entre o capital cafeeiro e o capital industrial. Esse processo permanece até 1929, quando, por efeitos da grande depressão e da crise cafeeira de 1929, houve uma mudança na dinâmica do crescimento do país (CANO, 1979; LORENZO, 1979.

O mercado local e regional criado pela economia cafeeira gerava, pois, a base para o desenvolvimento inicial da empresa. Porém, a busca por autonomia e independência foi uma das marcas da empresa, o que fez com que se procurasse, desde o início, o que havia de mais moderno no setor. Atecnologia disponível na época foi importante na definição do produto. A utilização de máquinas "monocilindro" está presente na produção de meias masculinas, desde 1921 até 1937. As matérias-primas utilizadas eram fios de algodão importados da Inglaterra e Egito.

Assim, várias viagens de prospecção tecnológica foram realizadas pelos seus dirigentes, para países que

\footnotetext{
${ }^{3}$ Há informações desencontradas a respeito do local de origem das máquinas. BRANDÃO E TELAROLLI, 1998, afirmam ser de São Paulo; nos trabalhos de LORENZO (1979), SANTOS (1997) e MORÁBITO (1997) consta que parte das máquinas veio do Rio de Janeiro e no estudo organizado por MANZOLI (2006) aparece a informação de que teriam vindo de Juiz de Fora/MG

${ }^{4}$ Pelos dados do censo industrial de 1907 havia nessa época no Brasil 200 fábricas de tecidos que empregavam cerca de 78.000 pessoas. Em 1920 esse número aumentou para 266 fábricas, com 115.519 empregos (41\% do emprego nacional). $\mathrm{Na}$ década de 1920 quando houve grande expansão da urbanização, principalmente em São Paulo, com aumento de importações e investimentos, também ocorreu grande avanço da indústria do vestuário. As principais matérias primas eram importadas, as fibras naturais e vegetais: lã, seda, algodão, juta e linho. A crise econômica de 1929 trouxe uma interrupção do investimento, que só seria retomado após 2a ${ }^{\mathrm{a}}$. Guerra Mundial. (Cano, 1979)
} 
oferecessem a tecnologia de que a empresa necessitava. As primeiras viagens ocorreram a partir de 1927, quando foram à Europa em busca de tecnologia de tingimento, e também para estabelecer os primeiros contatos com fornecedores de fios de algodão conhecidos como "Fio Escócia".

A cultura de verticalização, característica da empresa, ou seja, a busca para produzir internamente todos os equipamentos necessários, também tem início nos primeiros anos que se seguem à sua fundação. Seguindo o modelo das grandes corporações, e também pela inexistência de serviços especializados em Araraquara, a empresa procurou, desde cedo, se prover dos equipamentos necessários à produção de meias, seu principal produto. Começou a construir, ainda na década de 1920, uma ampla infraestrutura de produção, sendo que os primeiros empreendimentos nesse sentido se deram com a organização dos seguintes setores: oficina de reforma e manutenção de máquinas têxteis e oficina elétrica, com instalação de gerador próprio; setor de carpintaria e marcenaria. Este setor tem início pela necessidade de se produzir as fôrmas do concreto para a construção do prédio. Também a implantação da fábrica de caixas para embalagem de meias ocorreu em 1930.

A comercialização e todos os processos que envolvem esta área também foram uma marca forte na história da empresa. Desde os seus primeiros tempos de existência, a Lupo elegeu como seu cliente preferencial um público seleto, isto é, pessoas de gosto mais exigente, com condições financeiras para consumir um produto refinado e de qualidade. Assim, nos primeiros anos da fábrica, as meias, produzidas em sistema quase artesanal, eram vendidas na própria cidade, em cestas de taquara, na forma de vendas avulsas, sendo que também foi adotado nesse momento o regime de vendas consignadas.

A produção de meias de qualidade, com a utilização sempre renovada de tecnologias modernas, exigiu uma quantidade significativa de trabalhadores, cujo contingente se ampliou rapidamente, na medida em que a produção se expandia. O seu número passou de 22, em 1924, para 82 em 1929, com significativa queda em 1930, para 59 trabalhadores, possivelmente em razão da crise de 1929. (MANZOLLI, 2006)

Desde o início, em função das exigências e características do seu produto - meias -, que no processo de fabricação exige atenção, desvelo e delicadeza, atributos identificados com o trabalho de mulheres, e também por se tratar de uma tradição na indústria têxtil, a empresa optou pela mão-de-obra feminina, especialmente na produção. As primeiras trabalhadoras que se empregavam na Fábrica de Meias Lupo eram na maioria filhas de imigrantes europeus, alguns deles conhecidos dos proprietários, que faziam parte de ampla rede de imigrantes estabelecidos em Araraquara. Com as moças trabalhando na sala da casa do patrão e em contato direito com membros da família, que também desenvolviam atividades fabris, desde o início se foi construindo um padrão de relações de trabalho baseado na convivência com familiares, com relações pessoais e com contado direto entre patrões e empregados (CAIRES, 1999).

Nesse contexto, e de acordo com o padrão de relações de trabalho da época, era comum a presença física do patrão e seus filhos entre os trabalhadores. Era o patrão quem, de perto, coordenava pessoalmente a produção, zelando, sobretudo, pela qualidade do produto. Esta proximidade, no entanto, não impedia que os assuntos relativos ao trabalho fossem tratados com austeridade, garantindo a disciplina e a ordem na fábrica. Apesar disso, os trabalhadores eram atendidos em suas necessidades. Em consequência, pode-se afirmar que as relações de trabalho na empresa mesclavam tradição e racionalidade, indicando desde então os caminhos que trilhariam nos anos seguintes (CAIRES, 1999).

Desde os primeiros tempos, a gestão familiar e patriarcal foi uma característica da empresa. A tomada de decisões sobre produção, tecnologia, sistema de vendas e relações de trabalho está com a família, sobretudo os membros do sexo masculino, mas é o "pai" quem toma as decisões finais.

Outros fatores também foram fundamentais para o crescimento da empresa nessa primeira fase. Em primeiro lugar, e ainda sobre a importância da questão 
da comercialização, ressalta-se que a busca incessante por mercados ficou marcada indelevelmente como característica do papel da família na empresa. Por outro lado, ressalte-se também o rápido salto qualitativo, sempre na busca de tecnologia para o estabelecimento de um alto padrão de produção, e a consolidação nos mercados paulista e regional. Já neste período, conforme citado, inicia-se a formação de um corpo técnico, composto por mecânicos de manutenção de máquinas têxteis, formados na própria empresa, que posteriormente se constituirá em importante grupo dentro da escala de poder na empresa.

É, portanto, nesse primeiro período que começa a ser construída a sua cultura organizacional, com o estabelecimento e a afirmação dos valores que se farão presentes em toda a trajetória da empresa, até os dias atuais. Esses valores - autonomia e adaptabilidade, produção com qualidade (ligada à ideia de carinho e desvelo), austeridade; respeito às leis, ousadia para enfrentar desafios, honestidade, lealdade, informalidade nas relações, amor e dedicação ao trabalho, não desperdício e controle de gastos, independência financeira, e visão de futuro-, sempre retomados ao longo deste texto, foram gerados na sua primeira fase pelo seu fundador e reproduzidos pelos seus filhos e netos, nas gestões posteriores. Foram também compartilhados pelos primeiros líderes e demais trabalhadores que atuaram na empresa e fizeram da Lupo uma empresa de projeção nacional, marcada pela competência, mas também pela tradição e certa dose de conservadorismo. Tais valores foram também responsáveis pela consolidação de uma cultura forte, ao mesmo tempo em que contribuíram para a construção da identidade empresarial. Assim, quando o nome Lupo era pronunciado, a primeira imagem que se produzia era a de uma empresa sólida, eficiente, que primava pela qualidade, e se constituía em um espaço privilegiado para trabalhar.

Essa preocupação esteve fortemente presente nas decisões empresariais, desde o início, em especial na pessoa do fundador, que sempre exigiu e cuidou para que esse padrão se consolidasse. A qualidade, muito provavelmente, garantiu a boa aceitação do produto no mercado, assegurando a sobrevivência e o crescimento da Lupo, bem como permitiu que esta vencesse a concorrência e se sobressaísse na cidade e na região.

Em síntese, os primeiros anos da empresa, apesar de se aproximarem do que o sociólogo alemão Max Weber define como um modelo tradicional, isto é, com o líder conduzindo e orientando pessoalmente os trabalhos e mantendo relacionamento pessoal com os trabalhadores, já revelam a presença de uma dinâmica empresarial muito avançada. O mundo moderno conhecido como modelo industrial fordista - já podia ser percebido na empresa quando este padrão de produção ainda não estava claramente definido na indústria brasileira.

Dos ANOS 1930 até O FINAL dos ANOS 1970: CONSOLIDAÇÃO DA EMPRESA NO MERCADO NACIONAL

A partir de 1930 houve uma grande mudança no cenário econômico nacional. Com a crise de 1929, a atividade cafeeira perde a sua hegemonia. Isso faz com que a indústria, gradativamente, ganhe um papel mais importante na dinâmica econômica nacional. Aindústria têxtil, que já existia na época, passa a ser uma atividade importante, com forte crescimento, associado ao atendimento da demanda crescente. Esse período pode ser visto como muito positivo, e marcado, sobretudo, pelo início da produção e comercialização de fios sintéticos, fato que será de grande importância para setor têxtil brasileiro, pois significou a possibilidade de diversificação no uso de matérias-primas e consequente desenvolvimento de novos produtos.

A principal característica da Lupo observada no período foi o seu fortalecimento no mercado. Até os anos 1950, a produção de meias podia ser considerada pequena. Em 1950, houve grande expansão da produção, que atinge 164 mil dúzias de pares/ano e, entre este ano e 1965, a produção cresceu 53\%, tendo atingido 305 mil dúzias de pares/ ano (MANZOLLI, 2006).

Tendo se começado como uma pequena fábrica, tornar-se uma empresa de porte nacional não foi algo trivial. Em nossa opinião, o cerne da questão está na 
formação de uma forte identidade empresarial, que se originou juntamente com a construção de seu produto e de seu mercado. Por outro lado, a intensificação da verticalização das atividades, a valorizaçãa do conhecimento técnico interno e da inovação em gestão, na prática foram fatores importantes que já se observava desde os seus primeiros anos. Embora o comando continuasse nas mãos do patriarca e fundador, a presença dos filhos homens e mais velhos na administração, e também a contratação de profissionais nas áreas de administração e produção, revela o caminhar para um processo de relativa profissionalização, que terá como consequência a presença de controles e registros de dados e atividades realizadas pela empresa que indicam o crescimento do processo de racionalização. Esse fator permitiu à empresa sua adequação ao mundo do pós-guerra, antes mesmo que esse modelo de organização e de produção viesse se impor para o conjunto das empresas brasileiras. Ainda mais, esse procedimento pôde diferenciar bastante a Meias Lupo S/A frente ao padrão médio das indústrias têxtil e de confecções nacionais.

Em relação às relações de trabalho observa-se, nesse período, a continuidade e consolidação do padrão de relacionamento que vinha sendo construído desde o início da fábrica. Relações formais marcadas pela presença dos patrões no espaço de trabalho, com controle e vigilância direta da produção, dos comportamentos e atitudes, instituição de uma hierarquia rígida composta por mestres e contramestres, mesclam-se com um relacionamento informal e pessoalizado que incluía o atendimento das necessidades básicas dos trabalhadores, tais como assistência médica e outras benesses.

Por um lado pode-se afirmar que em muitos aspectos a Lupo segue o padrão de relações de trabalho presente na maioria das indústrias brasileiras, especialmente as têxteis, familiares e tradicionais. Por outro, é pioneira e antecipa-se, como, por exemplo, no caso da distribuição de lucros como $13 .^{\circ}$ salário para alguns empregados, cuja lei só será editada em 1962.

A 2. ${ }^{a}$ Guerra trouxe impactos diversos para a empresa. Aredução de fornecimento do fio de algodão estrangeiro fez com que se buscasse a matéria-prima na produção nacional. Porém, a sua escassez reduziu significativamente a produção e causou, talvez, a primeira crise vivida pela empresa. Todavia, vencida a crise no fornecimento de matérias-primas, a empresa assistiu a uma expansão comercial, com o início da exportação para os EUA.

A superação da crise, com recorrência à matériaprima brasileira, revela a capacidade de adaptação como um dos marcos da cultura da empresa que em outros momentos aparecerá de outra forma.

Assim, desde os anos 1950 a empresa, que já apresentava grau de desenvolvimento bastante considerável dedicando-se, até então, sobretudo à produção de meias masculinas, começou a investir em meias femininas e infantis. Isso deu início a uma trajetória de diversificação da produção e de reorganização de vários setores produtivos, tornando, nos anos 1960 e 1970, a Lupo uma empresa moderna e perfeitamente inserida no crescente mercado nacional de bens de consumo não duráveis que se expandia na época.

Nesse período, a cultura pela qualidade presente na empresa firma-se e intensifica-se. A escola de mecânica que se internalizou na Lupo levou à valorização da mão-de-obra técnica. Duas classes de mão-de-obra mecânica, isto é, mecânicos de máquinas (torneiros, frezadores) ligados à oficina de reforma $\mathrm{e}$ de construção de máquinas e mecânicos de manutenção de máquinas têxteis, que trabalhavam no interior da produção na fábrica, favorecem a formação de um sistema de poder desses técnicos. Especialmente os mecânicos de manutenção, como já mencionado, passam ser, cada vez mais, percebidos e tratados como trabalhadores fundamentais para o processo produtivo. A garantia da qualidade exigia um perfeito ajuste das máquinas, aliado ao bom desempenho das trabalhadoras e encarregadas de setores.

Nos 1960, a empresa firma-se como a única produtora de meias da cidade e região. O período é também marcado por crescimento do parque industrial com investimentos em máquinas, que passam de 224, 
em 1955, para 441 em 1970; pelo crescimento do número de trabalhadores empregados; e por investimentos no setor agropecuário. Também ocorreu

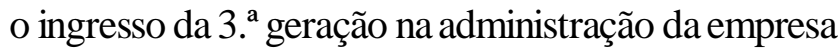
e a ampliação da participação de membros da família Lupo na vida pública da cidade e no âmbito federal.

A expansão da distribuição de produtos para os mercados internos e externos, especialmente EUA e alguns países da América do Sul, exigem a instituição da produção em 24 horas. Neste momento, há uma alteração na composição da força de trabalho ocupada na produção de meias. A proibição legal do trabalho feminino em horário noturno, em âmbito nacional, de conformidade com a legislação trabalhista do país, faz com que a empresa busque a mão-de-obra de homens - rapazes entre 19 e 25 anos. Estes jovens, no entanto, encontravam dificuldades de adaptação. Muitos se desligavam ou eram desligados da empresa, após curtos períodos de permanência. Permaneciam na fábrica aqueles que, após ingressar em curso de formação no Serviço Nacional de Aprendizagem Industrial (Senai), mantinham a aspiração de se tornarem mecânicos de manutenção, função cobiçada pelo prestígio gozado por esses profissionais, pelo bom salário, dentre outras vantagens. Essa dificuldade em fixar e manter a mão-de-obra masculina faz com que, mais uma vez, a empresa recorra ao trabalho das mulheres para a produção de meias.

Seguindo o modelo das grandes corporações, a Lupo construiu em torno de si uma gigantesca estrutura composta pelo prédio principal, escritório, oficinas de manutenção, reforma e construção de máquinas têxteis, carpintaria e marcenaria, oficina elétrica, gráfica, clube, residências para trabalhadores, restaurantes, lanchonetes, creche, dentre outros.

Aliás, no que se refere à tecnologia, e ainda em termos estratégicos, cabe destacar a construção de máquinas têxteis para a produção de meias simples, a partir de 1961. A presença de um técnico especializado e a organização de uma oficina de construção e reforma de máquinas no interior da empresa foi de fundamental importância para que isso acontecesse. Esse fato se deu em virtude de a empresa, em razão das dificuldades de importar maquinário, sentir a necessidade de produzir suas próprias máquinas.

Os anos da década de 1960 e 1970 correspondem, assim, à consolidação e ao coroamento do modelo de produção e gestão fordista e verticalizado, acompanhado de grande crescimento do parque industrial, de melhorias tecnológicas, expansão das vendas e diversificação dos interesses empresariais, produtos novos para a empresa e não para o setor. Aempresa, de postura aparentemente bastante conservadora, na realidade apresentou grande flexibilidade para adequação a padrões diversificados de produção e de gestão. Essa capacidade de adequação e adaptação e a busca constante de autonomia foram responsáveis pelo seu crescimento no período.

\section{ANOS 1980: CRISES E DIFICULDADES}

Os anos da década de 1980 foram bastante tumultuados para a economia e indústria brasileiras em razão dos planos econômicos recessivos e dos altos índices de inflação, o que vai refletir-se em importantes dimensões das empresas. A indústria têxtil e de confecções brasileiras, que desde a década de 1970 vinham tendo problemas para renovar o parque industrial, foram um dos ramos mais afetados. O fim do período de crescimento econômico, a elevação da taxa de inflação e a obsolescência que marcou os períodos anteriores começam a aumentar a partir de meados daquela década.

Para isso, colaborou a política industrial levada a cabo pelo governo no período, que, embora apresentasse alguns planos e projetos, foram poucos efetivados. Vejamos os fatos mais importantes. Em 1986, quando as defasagens na fronteira tecnológica passaram a pesar, surgiram estudos para automação e modernização do setor. Em 1986 começa a ser elaborado o plano de automação e modernização do setor até 2000, que previa, além do apoio do governo para financiar novos investimentos, isenção de tributos e plano de importação emergencial, enquanto o programa de modernização ia sendo mais bem definido. Foi apenas parcialmente implementado. Em 1988, a Nova Política Industrial (dec. Lei 2433,2434 e 2435) 
facilita a importação de máquinas; apoia investimentos em pesquisa e desenvolvimento. Surgiram também alguns programas de exportação. Em 1988 foram criados os Planos Setoriais Integrados - PSI - e o setor têxtil foi o primeiro a ser analisado. Havia uma visão integrada do setor e prevalecia a de cadeias produtivas. Todavia, o plano não foi implantado e as metas não se efetivaram (GORINI, 2000).

Os anos entre 1980 e 1991 na empresa Lupo foram marcados pela participação da $2 .^{a}$ e também da $3 .^{a}$ geração de membros da família na gestão da empresa. Apesar do forte clima de recessão e das dificuldades gerais da economia brasileira, a empresa continuou a expandir sua produção movida pela demanda interna ainda crescente e também pela forte estrutura produtiva criada. Todavia, também foi um período de forte crise, que culminou com a saída da família da direção da empresa. Entre os anos de 1991 e 1993 houve uma breve experiência de profissionalização da administração, tendo sido contratado um executivo do mercado para dirigi-la.

A busca por tecnologias modernas e desejo de aperfeiçoamento permaneceram, mesmo convivendo com as dificuldades enfrentadas pelo país, relativas às limitações para o desenvolvimento tecnológico e barreiras comerciais para importação de maquinário. A empresa continuou sua prospecção tecnológica em outros países. As viagens iniciadas pelos empresários, mais tarde acompanhados por empregados dos setores técnicos, para países como Itália, Inglaterra, Japão, na década de 1980, e mais recentemente Coreia e China, tiverame têm, até hoje, o objetivo de atualização e modernização do parque industrial e também e das formas de gestão.

Toda a estruturação da fábrica, bem como a constante busca de tecnologias, seja de máquinas, matérias-primas e mesmo em formas de gestão, refletem um valor introduzido pelo fundador na cultura da empresa, presente até hoje, e também está relacionado com a busca de autonomia e certa disposição da empresa para enfrentar desafios, adequando-se sempre às tendências modernas.

Os investimentos em tecnologias representam também decisões estratégicas fundamentais, adotadas pela empresa nos diferentes tempos e permitiram inclusive a diversificação dos produtos, bem como a introdução de algumas inovações.

Há que se destacar, contudo, que as tecnologias não estão dissociadas do processo de produção e organização do trabalho, que ao longo do tempo passa por mudanças, caminhando de um modelo taylorizado e rígido para outro mais flexível. No que se refere às relações de trabalho, é importante ressaltar que, neste momento, se observa mais um impulso rumo ao processo de racionalização, o que, aliás, vem se observando no cenário empresarial brasileiro. A mudança na denominação do setor de relacionamento com os trabalhadores, de Departamento de Pessoal para Relações Industriais; a organização do Centro de Treinamento, favorecido pela lei de incentivo à formação profissional; a contratação de uma psicóloga; e a instituição de testes científicos no processo de recrutamento e seleção são marcas desse processo, que se acelera no período.

Outro fator que possivelmente tenha contribuído para essas mudanças foi a presença de movimentos sociais envolvendo a classe trabalhadora no Brasil. As lutas que se travaram entre capital e trabalho nos anos 1980, em particular o movimento grevista dos metalúrgicos, que marcou presença no $\mathrm{ABC}$ paulista, ao se expandir para outras regiões do país, inclusive para Araraquara, levou os empresários a buscarem alternativas de prevenção. Nesse momento, a empresa reforçou a sua orientação legalista. A atenção e o cuidado no cumprimento das leis, que já eram uma tradição, tornaram-se ainda mais preocupantes. Outros equipamentos, como lanchonete e, sobretudo, a creche, foram instalados com vistas a cumprir rigorosamente as exigências legais.

Também ocorreu uma maior racionalização nos controles de produção com a criação dos departamentos de PCP, métodos e processos, organização do setor de relações de trabalho, dentre outros. O fato de a empresa manter autonomia em relação à elaboração de programas, isto é, não comprar sistemas operacionais e sim produzir os seus 
próprios programas e sistemas, fortalece um grupo de profissionais ligados ao setor de informática. Tal fato também foi gerador de conflitos na medida em que trouxe novos grupos de poder, desestabilizando relações constituídas muito rigidamente. O encolhimento do poder dos técnicos (mecânicos de manutenção) e o fortalecimento do poder do grupo de informática pesaram na quebra das relações de poder até então predominante

A década de 1980, particularmente, representa um momento de significativas mudanças nas relações de trabalho com a adoção de técnicas de relacionamentos e formas de gestão da mão-de-obra importadas de outros países, em particular do Japão. Isso é traço indicativo de mais um valor presente na cultura da empresa e que está ligado à sua ousadia para inovar e enfrentar desafios, bem como capacidade de se adaptar. Ao mesmo tempo, essas ações podem representar estratégias de atualização em termos de gestão e, até certo ponto, se tornam necessárias para acompanhar as tendências que se desenvolviam no mundo capitalista, e que também exigiam certa ruptura com o rigor do modelo fordista de acumulação.

Os fatos que mais marcara a história da empresa nos anos 1980 foram: a) as novas formas de gestão da produção e administrativas e marcam o fim do Centro de Processamento de Dados (CPD), que usava cartões perfurados, e a implantação do setor, que passa a usar as fitas magnéticas. Essa inovação organizacional permitiu maior armazenamento de dados, possibilitando maior controle da produção. Os programas eram todos realizados na própria fábrica no departamento de informática; b) organização dos Setores de Programação e Controle da Produção (PCP) e Métodos e Processos (M\&P) - com a introdução de cronometragem e cronoanálise; c) organização de setor de criação com a contratação de estilistas; d) chegada das Máquinas Nagatas em 1984, o que representou grande marco de inovação em processo e produto, ao permitir a confecção do punho dobrado e desenho da meia, torna a Lupo pioneira neste segmento; d) em 1986 foi registrada a primeira experiência de produção em célula, que pode ser considerada uma experiência bem inovadora para a época, mas realizada com as máquinas antigas. A experiência fracassou porque começam surgir conflitos por causa de salários diferenciados exigidos pelo novo processo; e) em 1987 chegaram as primeiras máquinas semieletrônicas com Duplo Cilindro; f) a máquina Mágica, que trazer grande avanço na produtividade; g) em 1988 teve início a produção de cuecas; h) ainda em 1988 foi lançada a Meia da Loba (antiga meias de senhoras), o que vai propiciar o aumento da participação no mercado de meias femininas; e, em 1989, chegou a primeira máquina de recobrir o elastodieno.

Com todas as mudanças realizadas, a produção de meias na década de 1980 cresceu de 1427.394 para 2377.244 pares por ano, o que pode ser verificado no Gráfico 1. Todavia, não evitou a forte crise que veio principalmente pelo endividamento da empresa e queda da produtividade em tempos de elevada inflação. Apesar dos esforços na busca por produzir suas próprias máquinas, a tecnologia ultrapassada tende a exigir grande quantidade de mão-de-obra para sua utilização, o que vai contribuir para a elevação do número de trabalhadores, que atinge seu recorde em 1988, com um total de 3.368 empregados. O alto número de trabalhadores gerava despesas elevadas, sendo que salários e encargos passaram a ter peso significativo nas finanças da empresa, a qual, por sua vez, também enfrentara outras dificuldades familiares, exigindo uma reordenação e reorganização da vida empresarial. 
Evolução da produção em dúzias

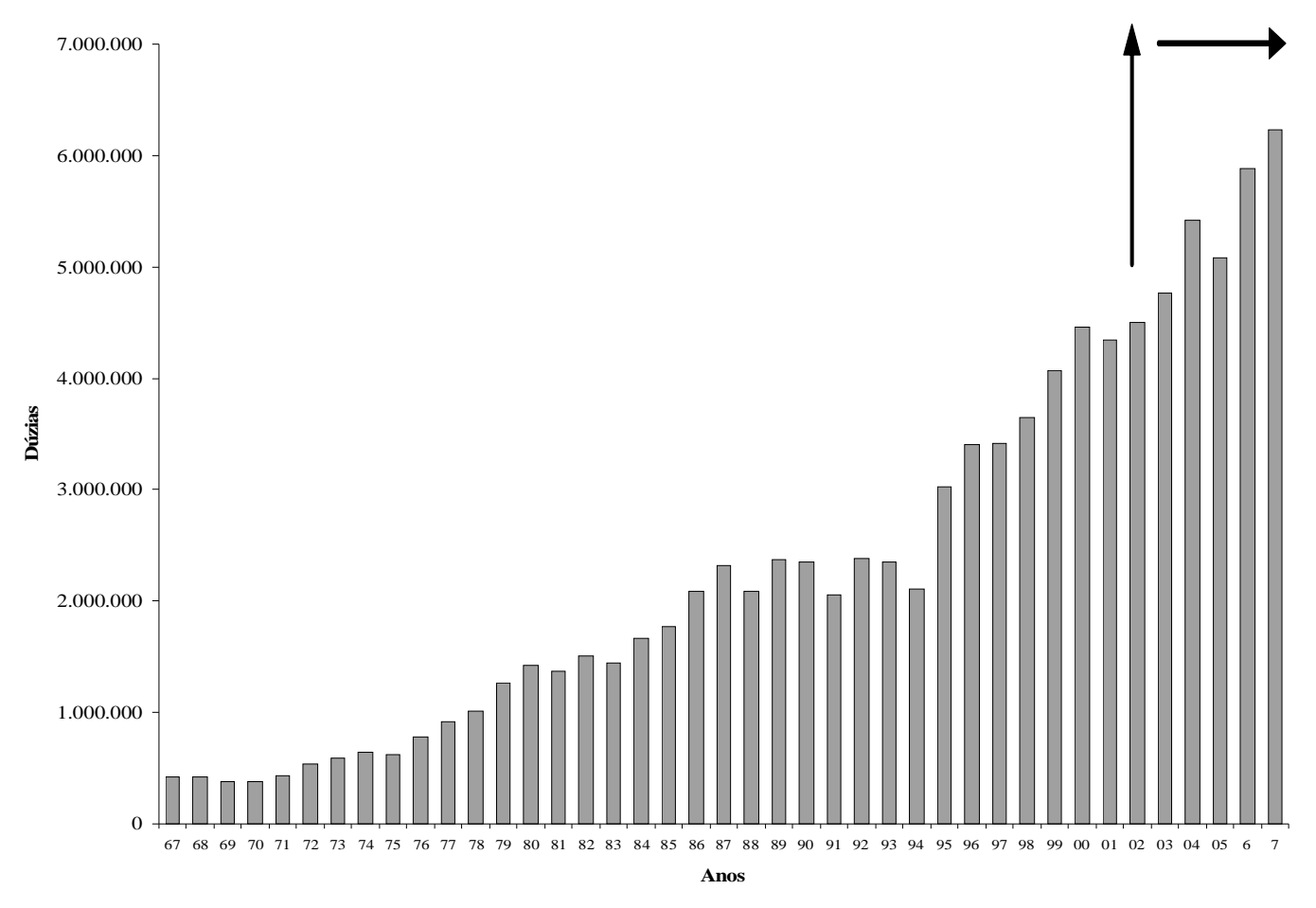

Gráfico 1 - Evolução da produção por dúzias 1987-2007.

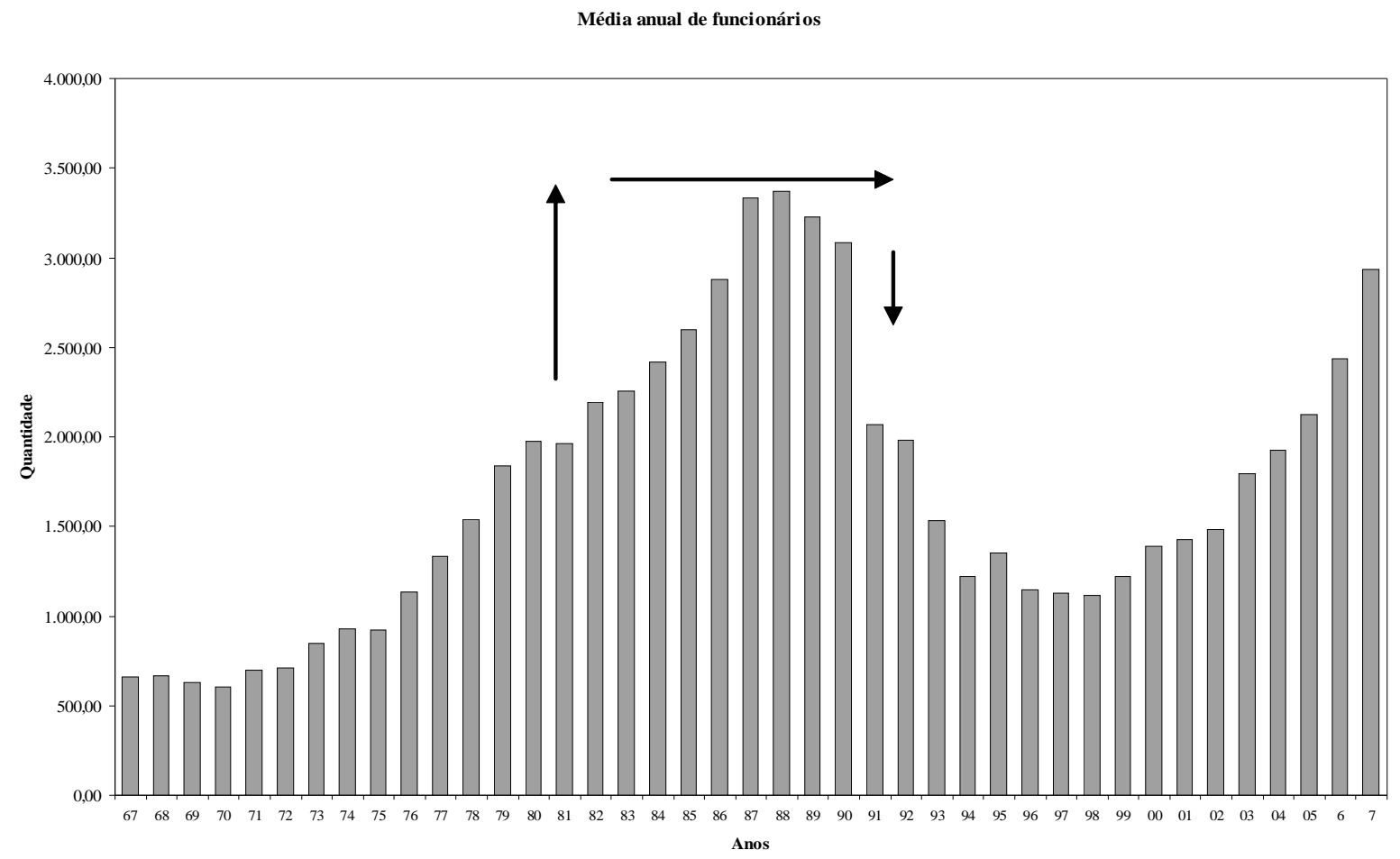

Gráfico 2 - Média anual de funcionários 1987-2007. 
No gráfico 2 pode-se verificar, pelas setas indicativas, o elevado crescimento do número de funcionários na década de 1980. Cabe mencionar que a ambiguidade de relações, criada pelo esforço para se adequar às exigências da década, levou seus dirigentes a procurarem alternativas modernas de gerenciamento da mão-de-obra e da produção e produtos.

Embora os anos 1980 tenham representado um primeiro e grande esforço de percepção das mudanças iniciais que o mundo globalizado imporia, foi também um período de gestação de conflitos, cujo desfecho causaria sérios problemas para a empresa.

\section{OS ANOS 1990: CRISE E SUPERAÇÃo}

Nos anos 1990, o cenário macroeconômico brasileiro tornou-se mais complexo como agravamento da crise e da inflação e, pode-se mesmo dizer, que era perverso à atividade produtiva. Sob forte inflação e recessão internas, iniciou-se um processo de abertura comercial acelerada, com redução drástica e rápida das alíquotas de importação e de diversas restrições não-tarifárias às importações. A recessão no mercado doméstico (1990-1992) e câmbio sobrevalorizado (94-99) não beneficiaram as indústrias. Aindústria têxtil foi um dos setores que mais sofreram com o aumento das importações, com o fechamento de empresas e forte redução do emprego (GORINI, 2000).

Em 1991, frente à forte crise mencionada, assumiu a direção da empresa um profissional contratado no mercado. $\mathrm{O}$ acompanharam alguns profissionais de sua confiança. Os problemas, no entanto, estavam apenas se iniciando. Frente à crise anunciada, a nova administração realizou um diagnóstico que apontava como principais problemas a existência de um parque industrial defasado e problemas com a produção, cuja solução demandava investimentos elevados, principalmente em processos novos.

As principais mudanças ocorridas no período foram a aquisição das primeiras máquinas eletrônicas importadas para a confecção de meias esportivas e a compra da Meianyl, uma empresa localizada em São Paulo e que se encontrava em processo falimentar. O que se pretendia era criar uma linha de produto alternativa e usar a melhor tecnologia disponível.

As formas de gestão e o estilo utilizado na condução dos processos de implementação das propostas, no entanto, eram bastante diferentes daqueles que até então significavam a marca da empresa. O novo diretor tentou também implantar modelo de terceirização voltado para fora, com a importação de meias da Coreia do Sul.

A nova direção buscou aprofundar uma forma de produção marcada por uma estratégia bem diferenciada que, na realidade, já vinha sendo buscada pela empresa desde o início dos anos 1990, e que apenas no final desta década seria uma rotina no mundo empresarial. Trata-se da produção induzida pela demanda. Até então a rotina era a de produzir sempre com grandes estoques. A partir dessa época, o ajuste da produção se faria pela demanda, procedimento que exigiu grandes adaptações nos processos produtivos. Essas adaptações, no entanto, só vão de completar bem posteriormente, em meados dos anos 1990, quando a Lupo vai verdadeiramente programar seu processo de reestruturação produtiva 5 .

A ênfase ao sistema just in time visava integrar melhor a empresa no mundo global: significava, nesse caso, manter estoques pequenos e produzir a partir dos requerimentos da demanda. Buscava sempre inserir a empresa em mercados globais. O grande problema, no entanto, foi a questão dos custos de produção, que se ampliavam, associados a um processo de endividamento crescente.

Um fator que contribuiu para o aprofundamento da crise foi o não reconhecimento da administração profissional pela base da empresa, diretoria e trabalhadores em geral. Na realidade ninguém

\footnotetext{
${ }^{5} \mathrm{Na}$ realidade as primeiras experiências de reestruturação empresarial se iniciaram nos anos 1980, na época conhecidas como reengenharia ou implantação de processos de qualidade total.
} 
aprovava a administração profissional. Com a saída dos diretores e membros da família, restou um clima geral de desânimo. Porém, a cultura empresarial continuava forte e seria de grande ajuda para $\mathrm{o}$ encaminhamento do futuro.

Da perspectiva da economia brasileira cabe destacar que os primeiros anos da década de 1990 anunciavam, também, uma nova dinâmica no mercado mundial, e a abertura comercial da economia brasileira trouxe redução generalizada das restrições ao comércio. Mas, principalmente, impôs novos movimentos ligados à nova forma de organização da atividade econômica e produtiva. Dentre as principais mudanças trouxe a presença das empresas multinacionais, e a organização de cadeias globais de produção, comercialização e distribuição de mercadorias.

Com a abertura comercial no Brasil, também a indústria têxtil no Brasil passava por profundas transformações desde o início da década de 1990 que, somadas às medidas do Plano Real, tiveram como resultado forte elevação das importações, reflexos expressivos na retração da produção, e, sobretudo, na redução do emprego (SERRA, 1988).

No caso da indústria têxtil, também como características do processo de reestruturação, a expansão mais expressiva das importações foi localizada em dois produtos principais: fibras de algodão, por conta da forte retração da produção doméstica em meados dos anos 90, e fios e tecidos artificiais e sintéticos. Esses fatos serão fundamentais para o encaminhamento do setor a partir de meados da década. A forte retração do emprego no setor decorreu não apenas da redução da produção, mas também da reestruturação tecnológica e produtiva das empresas têxteis no Brasil, já que substituíram as antigas máquinas de tecer por modernos teares que requerem um contingente muito menor de trabalhadores (LUPATINI, 2004).

Este era o cenário nacional no qual a Lupo teria que enfrentar, a partir de setembro de 1993, a mais forte crise empresarial e comercial de sua existência, que quase resultou no encerramento de suas atividades.
Nesse mesmo ano, o fim da gestão da empresa realizada por profissional contratado no mercado, considerada desastrada, se deu com a demissão do diretor. Também a saída do gerente de vendas e a promoção de um novo gerente nacional de vendas marcaram o novo encaminhamento da crise.

A reversão foi um processo longo e doloroso do qual resultaram grandes mudanças e surgiram novas lideranças. No auge da crise e com a missão de "talvez vender a empresa", assume como diretorasuperintendente da empresa um membro da família, filha de uma herdeira, mas com elevada qualificação para o cargo.

Buscando condições para equacionar o problema financeiro, a nova diretoria vai buscar recursos no sistema bancário e solicitando à família o prazo de um ano para atuar na empresa. Apesar da crise, o retorno da família à direção da empresa foi muito bem recebido pelos funcionários e o bem-estar voltou (MANZOLLI, 2006). Esta forte característica da cultura empresarial formada ao longo do tempo, e que atribuía à presença da família um traço de força e estabilidade, indubitavelmente foi ponto importante para a superação de uma situação que muitos consideravam perdida. Reconhecendo a importância do passado e assumindo um diálogo franco com a base administrativa da empresa, a nova diretoria tomou atitudes altamente inovadoras que foram importantes para a superação da crise, montando um quadro gerencial de confiança, e reduzindo os gerentes de nove para seis, promovendo grande reestruturação produtiva e organizacional.

Mas o passo principal foi a aquisição de máquinas semieletrônicas da Coreia, as máquinas Kukje. Este foi um traço marcante, pois não conseguiram comprar as italianas, que eram as melhores. Assim, começou o longo processo recuperação da empresa.

Dentre as inovações também foi adotado um modelo de gestão pautado em decisões colaborativas com a administração participativa, com frequentes consultas às bases, o que garantiu apoio desse segmento e reduziu o filtro das informações, ou seja, as informações passaram a ser diretas, estabelecendo-se um sistema de comunicações mais efetivo. Aredução de despesas 
e melhor funcionamento das linhas de montagem levaram à desativação da antiga unidade localizada em área central da cidade e transferindo toda a produção para uma fábrica nova, em área mais afastada. Foram reunidas as áreas comerciais e de produção, o que favoreceu uma maior aproximação entre esses setores, ao mesmo tempo em que facilitava a responsabilidade sobre a área de produção e a de desenvolvimento técnico e de novos produtos.

Um dos aspectos mais inovadores propostos pela nova diretoria foi a introdução e consolidação de um sistema de franquias, sistema de iniciativa tímida de início, mas que se tornou um grande canal de comercialização da produção. Outro aspecto relevante dentre as inovações em gestão foi o enfrentamento de um estilo de produção para os mercados globalizados, ou seja, produção para o atendimento às demandas específicas, produtos específicos em quantidades limitadas - não há estoques grandes, apenas pequenos e para alguns produtos. Foram fechados os antigos escritórios regionais de Belo Horizonte, Fortaleza e Porto Alegre, que existiam desde os anos 1960, mantendo-se apenas os de São Paulo e Rio de Janeiro. Com esse conjunto de medidas, um novo ponto de equilíbrio entre custos/produção/quantidade de mãode-obra e comercialização.

Um dos aspectos fundamentais que se observou na primeira metade dos anos 90 foi o processo de desmontagem da estrutura verticalizada que, até então, caracterizara o formato organizacional da empresa. Um modelo mais enxuto começou a ser construído, a partir do fechamento de alguns setores, como o de oficinas de reformas e construção de máquinas, carpintaria e marcenaria, gráfica e oficina elétrica, iniciando-se a terceirização de alguns setores. As terceirizações representaram nesse momento uma nova estratégia produtiva e administrativa, que visava desincumbir a empresa de atividades consideradas subsidiárias à produção, permitindo uma maior focalização em sua atividade principal.

Como explicar a saída da crise e a retomada da produção? A partir da análise realizada é possível propor quatro fatores que foram fundamentais nesta passagem. Emprimeiro lugar, e talvez o mais importante para explicar a retomada da empresa, foi a imagem da força da família, muito presente na cultura da empresa, associada ao conhecimento pessoal da diretora para as questões técnicas e tecnológicas e a sua disponibilidade para o aprendizado. Sem a modéstia e a força para admitir a importância de aprender para enfrentar novas situações, não teria buscado novos valores empresariais, como a importância do empreendedorismo, da inovação e da prospecção tecnológica, já quase esquecidos pela empresa. Em curto espaço de tempo, e com o apoio dos trabalhadores, a situação da empresa começou mudar. Mas também foi importante o apoio e certo distanciamento "necessário" da família.

Em segundo lugar, uma combinação de aspectos da nova gestão da tecnologia e da produção que possibilitaram um novo patamar de equilíbrio na empresa. A "lição de casa" realizada com a execução da política de reestruturação produtiva foi feita com rigor. Seus principais pontos foram os seguintes: intensificação da automação, diversificação de produtos, redução drástica da mão-de-obra e melhorias nas condições de comercialização, responsáveis pelo aumento da produtividade da empresa. Na reestruturação buscaram-se não só bons produtos, mas a implantação de um sistema de produção que se caracterizou pela gestão mais integrada entre produção, tipos de produtos, estoques possíveis e vendas, principalmente. Houve certa proximidade com modelos de produção sugeridos pela indústria metalúrgica e/ou mecânica, nas quais há muitos produtos em vitrines para serem oferecidos e vendidos. Esses elementos reafirmam uma característica forte da cultura organizacional da Lupo, relacionada com a capacidade de adaptabilidade da empresa à "situações desafiadoras".

Em terceiro lugar, apesar da difícil condição da indústria têxtil e confecções no Brasil nos 1990, a economia brasileira começou a ajudar ao caminhar por uma trilha mais firme com o Plano Real e o fim da inflação.

Em quarto lugar, e de num ponto de vista mais 
técnico e interno à empresa, as mudanças técnicas realizadas. Ressalte-se que já havia, desde anos anteriores, claros diagnósticos que indicavam a presença de umparque tecnológico bastante defasado. $\mathrm{O}$ grande problema foi que, no período anterior, as soluções buscadas romperam excessivamente com as formas mais tradicionais por meio da qual a empresa sempre enfrentara seus problemas. Este havia sido um fator de forte desequilíbrio. Com a volta da família na direção da empresa, mas com uma administração movida pela forte presença de empreendedorismo, inovação e conhecimento, a retomada de uma perspectiva de gestão de "dentro para fora," os trabalhadores se sentiram mais confiantes e mais dispostos a enfrentar os problemas. Longe de qualquer raciocínio conservador, a importância da cultura empresarial estava mais uma vez evidenciada. O grande esforço dos mecânicostécnicos, que rapidamente se transformaram em mecânicos de máquinas informatizadas, demonstra amor ao trabalho e à empresa.

Esses aspectos foram responsáveis pela introdução de uma nova lógica empresarial que, em verdade, já estava presente no mundo empresarial desde os anos 1980. Mas na empresa o processo de incorporação dessas mudanças foi bastante longo e sofrido. As consequências poderiam ter sido mais graves. A empresa quase fechou, porém, as mudanças nos grupos de poder e $\mathrm{o}$ apoio da base foram fatores essenciais para a conquista da estabilidade e a retomada do crescimento.

Em 1995, com a mudança na regionalização das máquinas ocorrida no país (LUPATINI, 2004), houve mudanças na estratégia da empresa que, reconhecendo que o parque industrial ainda estava defasado, iniciou nova fase de compra de máquinas eletrônicas que mudaram o perfil produtivo da empresa. As novas máquinas automatizadas dos coreanos compradas com aval, porque a empresa ainda não havia recuperado a capacidade de pagamento, foram fundamentais para a retomada do crescimento.

Em 2000 a empresa já tinha claro um novo rumo. Havia uma estratégia claramente definida e um modelo de gestão pautado em decisões colaborativas e ações concretas. Entre 2000 e 2001 a empresa investiu ainda mais em automação, comprando máquinas italianas. Assim, a partir de 2001 estava montado seu novo parque produtivo, pronto para atender a mercados variados e flexíveis.

Com o parque produtivo inteiramente automatizado e a retomada da produção na empresa, a partir do ano 2000 pode ser percebido que, nas características de sua mais tradicional cultura empresarial, agora estão presentes fortes traços do mundo pós-fordista: produzir e vender produtos diferenciados, em condições de produção flexíveis para mercados instáveis. Dois aspectos passam a ser prioritários para a empresa: questões tecnológicas e questões organizacionais. Do ponto de vista estrutural, as preocupações são com as instalações, capacidade e tecnologia. Do ponto de vista organizacional, as preocupações mais relevantes são: a organização dos processos e capacitação dos Recursos Humanos (RH).

As mudanças que ocorreram na base produtiva, na medida em que se revelaram pró-ativas, e responsáveis pela saída da empresa da forte crise que a assolava, foram incorporadas na cultura empresarial. Não se produz mais apenas meias, mas outros produtos foram incorporados na produção e a diversidade passou a ser a norma. O empreendedorismo, a inovação e o conhecimento como forma de valor para o indivíduo e para a organização se tornou um requisito básico. Saber pensar, saber aprender, saber mobilizar, saber transferir, saber engajar-se, ser criativo, ter visão estratégica e assumir responsabilidade passaram a ser elementos para a agregação de valor. Os diretores de sucesso na empresa revelaram claramente a incorporação desses valores em suas visões de gestão.

Com isso ganham espaço e se intensificam os programas de treinamento, que ocorrem por meio de visitas ao processo produtivo, palestra com fornecedores, treinamento sobre fiação, informações sobre qualidade e produtividade; implantação da escola de primeiro e segundo graus para os operários, programas de estágio de operários nos fabricantes de máquinas e equipamentos; e maior participação nas 
decisões da empresa, criando comprometimento.

Destaque-se que até a capacitação dos jovens da família e da 4. ${ }^{\text {a }}$ geração Lupo que, diferentemente de seus pais e tios, não participaram da saga dos primeiros anos de atividades da empresa, passou a ser uma preocupação da diretoria, que reconhece a necessidade de que a história e a dinâmica da empresa devam ser objeto de estudo e análises e devem ser incorporadas por aqueles que pretendem participar da gestão da empresa.

O ambiente de trabalho na Lupo vem passando por sensível mudança. A preocupação com os movimentos do mercado passa a exigir: equipe de estilistas especializados; private Label; participação em feiras; utilização de fornecedores como prestadores de serviços. Por outro lado, torna-se necessário ficar antenado aos consumidores, procurando captar seus desejos e necessidades, transformando-os rapidamente em produtos oferecidos. Neste momento ocorre a criação do Serviço de Atendimento ao Consumidor (SAC), que cria um link entre as empresas e os consumidores; programa de treinamento dos lojistas para transformá-los emagentes de vendas; expansão do sistema de franquias.

\section{OS DESAFIOS DA GLOBALIZAÇÃo}

Nos últimos anos, chama a atenção o significativo crescimento da Lupo retomando, assim, uma trajetória ascendente de aumento da produção e de vendas, de expansão do número de trabalhadores e, principalmente, de inovação em produtos, gestão administrativa e de marketing.

Entre os anos de 2002 até 2007, o crescimento da produção na empresa em dúzias foi de $38,56 \%$. Porém, é necessário considerar que este crescimento se refere aos diversos produtos hoje produzidos pela empresa, que vão além da sua tradicional produção de meias.

A diversificação de produtos, na realidade, foi o fator responsável pela elevação da produção e pela melhoria no desempenho da fábrica. Atualmente, a produção de cuecas, lingerie e, principalmente, produtos "sem costura" tem representado um mercado promissor para a empresa. Observa-se, porém, que o mercado dos produtos "sem costura" é bem recente. Nasceu em 2003. Naquele ano a empresa produziu 37 mil dúzias/ano da linha "sem costura" e, em 2007 a produção cresceu extraordinariamente para 487 mil dúzias/ano. A produção de cuecas para o mesmo período cresceu de 589 mil dúzias/ano para 745 mil dúzias/ano em 2007, sendo que havia a expectativa de aumento de produção para mais de 1 milhão de dúzias em 2008. Por outro lado, o segmento de "meia colante" passou por forte redução no consumo, tendo grande parte da capacidade produtiva deste produto se transformado em "segunda pele", um outro produto com boas vendas.

Esses novos indicadores de desempenho mostram que o perfil da empresa se alterou, assim como mudou a sua posição na cadeia produtiva: até o ano de 2000 a empresa, como já mencionado, que operava com tecnologia de base eletromecânica, foi fortemente automatizada. Contudo, a produção de peças "sem costura", especialmente cuecas, continua exigindo considerável quantidade de mão-de-obra. Este fato pode ser um dos mais sérios conflitos que a empresa poderá enfrentar em futuro próximo, ou seja, a automatização traz uma nova modalidade de dependência de mão-de-obra qualificada.

Para avaliar as alterações no perfil produtivo da empresa cabe destacar as mudanças ocorridas no mercado de meias que envolvem produção, tecnologia e consumo. Segundo o Instituto de Estudos e Marketing Industrial(Iemi), em 2007 a produção de meias no Brasil cresceu de 251 milhões de pares/ano para 520 milhões de pares/ano, indicando um crescimento de mais de $100 \%$. Como indicativo do consumo de meias, este dado significa uma média de 2,8 pares por habitante, o que é ainda muito baixo quando comparado com o de outros países. O consumo médio de países como a Itália, por exemplo, hoje é de aproximadamente 6,2 pares por habitante.

Neste cenário a Lupo ocupava, em 2002, 9\% do mercado nacional, fatia que em 2007 se expandiu para 11,58\%. Aparentemente, haveria muito a crescer para ocupar este mercado, porém, as mudanças ocorridas no setor produtivo de meias foram grandes e 
caminharam para a banalização das condições e do processo de produção. Por um mecanismo, típico das economias capitalistas, o preço das máquinas tende a cair com a expansão do consumo, mesmo que sejam máquinas modernas e automatizadas. É preciso considerar que toda tecnologia percorre um caminho: nasce "quase" rústica, desenvolve-se e depois tende à banalização. É o que aconteceu no Brasil, onde, desde o ano 2000, vêm caindo os preços das máquinas de produzir meias, mesmo considerando as melhorias e a automação das mesmas. Este fato impôs mudanças para as fábricas de meias, que perceberam e puderam enfrentar o problema. No Brasil existem atualmente cerca de 10 mil máquinas de produzir meias, das quais 4 mil estão nas mãos de quatro grandes fabricantes, sendo a Lupo um deles. Pode-se concluir, por esta razão, que há uma pulverização de pequenos e médios produtores no país, e que produzir meias deixou de ser um negócio apenas para a grande empresa. Em outras palavras, a queda no preço das máquinas modernas abriu a possibilidade do surgimento de novos empreendimentos, ou seja, reduziram-se fortemente as barreiras à entrada de novas empresas no mercado, permitindo, assim, o surgimento de fábricas de menor porte.

Também contribuiu para a deterioração das condições do mercado de meias, no Brasil, o significativo aumento das importações, em razão da queda dos preços médios internacionais. Em 2002, o país importou 6 milhões de pares e, em 2007 (até o presente), as importações foram de 25 milhões de pares, com tendência a crescer. $O$ preço médio hoje é de US\$ 0,30 (30 cents) com tendência a maior redução. No mercado interno, o preço médio de meias por dúzias também tende a cair, acompanhando a tendência observada no mercado internacional. No Brasil caiu de $\mathrm{R} \$ 38,63$, em 2006, para 37,86 em 2007 , e apontava para nova queda em 2008 , segundo o Iemi (2007).

Porém, ao mesmo tempo em que acabam as antigas barreiras tecnológicas para a produção de meias, o avanço tecnológico faz surgir novas barreiras que realinham o mercado para outro patamar de negócios. É o caso, por exemplo, das barreiras por dificuldades de acesso ao mercado de insumos de fios e, principalmente, barreiras comerciais decorrentes das dificuldades em penetrar em novos mercados para venda dos produtos. Nesses casos, quando essas barreiras são muito fortes, a força da marca aliada à tradição comercial de uma empresa podem ser fatores de competitividade essenciais para a sua sustentação no mercado. Esse foi o caso da Lupo. Ao lado da busca de novos produtos, o lado comercial da empresa ficou mais evidenciado na medida em que esta soube colocar sua produção em sua grande rede de distribuição, nas franquias e outros pontos. Do lado produtivo, além dos novos produtos, a empresa teve a habilidade para reaproveitar e requalificar seus funcionários para as novas tecnologias.

No entanto, mesmo esses mercados de novos produtos já começam a atrair novas empresas e, em consequência, enfrentar forte concorrência no mercado interno. Também para esses produtos, as condições de produção vêm se alterando com as mudanças rápidas ocorridas na tecnologia e com o acirramento da concorrência. Para enfrentar essa nova situação a empresa vem, como se destacou, incorporando novos métodos e novas tecnologias de produção e gestão, microeletrônica, desenvolvimento de novos produtos, principalmente com o uso de fibras sintéticas.

\section{Considerações finais}

A história da Lupo é um bom exemplo de uma empresa familiar que se dedicava a apenas um produto, enfrentou fortes crises e um duro processo de reestruturação produtiva no final do século XX e início do XXI. Em seus 89 anos de existência, para manter-se competitiva foi levada a montar, desde os anos 1930, uma estrutura verticalizada que nos anos 1970 se revelou um moderno parque industrial, mas teve de ser inteiramente reestruturado. Tendo criado desde a época do fundador sólida cultura empresarial, soube conciliar a manutenção de aspectos familiares, com competitividade e empreendedorismo. Diversificou sua produção para adaptar-se às novas 
condições de mercado.

Para o século XXI, no entanto, os desafios são imensos. Olhar o futuro significa ter em foco as principais mudanças tanto quanto aos materiais quanto tecnológicas. Quanto aos materiais, a grande tendência ainda é a microfibra, que se aproxima do algodão e traz grande sensação de bem-estar. Do ponto de vista tecnológico, três grandes tendências podem ser identificadas para a indústria têxtil e confecções. Em primeiro, a nanotecnologia, que parece ser uma das principais rotas que deverá ser seguida pela indústria têxtil e do vestuário nos próximos anos, por meio da crescente difusão dos chamados "tecidos inteligentes": materiais "phase change" (frio e quente); materiais "shape memory" (modelador); materiais crômicos (trocam de cor).

Em segundo, a questão do desenvolvimento de produto, design e moda, que mostra o encurtamento do tempo de vida das linhas de produto e o aumento da importância da moda, e aponta também para a tendência à customização. Em consequência, se impõe a adoção de novas tecnologias, que confiram maior rapidez ao desenvolvimento de produto, bem como maior rapidez e flexibilidade ao processo produtivo.

Em terceiro, a questão da normatização. Este é um aspecto fundamental. A criação de normas e padrões para os artigos têxteis, do vestuário e a padronização de características dos produtos, em termos de tipos, modelos e tamanhos, devem se desenvolver com vistas ao atendimento dos requisitos dos compradores e à melhoria do produto ao consumidor final (GARCIA, 2007).

Nesse quadro de possibilidades e expectativas, a questão que fica para o caso da Lupo é a de que até que ponto os valores construídos, associados ao conhecimento e à inovação poderão efetivamente ser instrumentos de adaptações e enfrentamento do mundo globalizado.

\section{REFERÊNCIAS}

BRANDÃO, IGNÁCIO DE LOYOLA;
TELAROLli, RODOLPHO. Addio Bel

Campanile: a saga dos Lupo. São Paulo, Global, 1998.

\section{CAIRES, ÂNGELA CRISTINA RIBEIRO. Fios}

Tecidos: a malha da terceirização no setor têxtil em Araraquara. $380 \mathrm{f}$. Tese (Doutorado em Sociologia) - Faculdade de Ciências e Letras da Universidade Estadual Paulista "Júlio de Mesquita Filho", Araraquara, 1999

\section{CANO WILSON. Raízes da concentração industrial em São Paulo. São Paulo. Difel, 1979.}

CASTANHEIRA, JOAQUIM. O terceiro será o primeiro: a onda da terceirização engolfa as empresas brasileiras - e quem não embarcar rápido nessa corre o risco e ficar comendo poeira. Revista Exame. São Paulo, n.512, 1992.

\section{CHANDLER JR A. La Main Invisible dês} Manangers, Paris: Economica, 1988.

\section{CHIAVENATO, IDALBERTO. Gestão de}

pessoas: o novo papel dos recursos humanos nas organizações. Rio de Janeiro, Campus, 1999.

FLEURY, MARIATEREZALEME. Cultura de Empresa e Novas Formas de Gestão da Força de Trabalho. Revista Ciências Sociais Hoje. ANPOCS, 1991, p. 245-261.

GARCIA, RENATO DE CASTRO e HIRATA, CELIO - "Impactos da abertura comercial sobre a dinâmica da indústria têxtil". LEP, Campinas 1995.

GORINI, ANA PAULA FONTENELLE "Panorama no setor têxtil no Brasil e no Mundo: Reestruturação e Perspectiva. Fórum de competitividade do Comercio Exterior". MDIC. BNDES. 2000 
HAMEL GARY - Inovação Sistêmica e radical. In: HSM Management, jan.fev. 2003.

\section{LORENZO. HELENACARVALHO DE. Origem} e crescimento da indústria na região Araraquara- São Carlos 1890- 1970. Dissertação (Mestrado) - FFCL/USP. São Paulo 1979.

LUPATINI, MARCIO PASCHOINO - "As transformações produtivas na indústria têxteis vestuário e seus impactos sobre a distribuição territorial da produção e a divisão do trabalho setorial". Cap 2 . Dissertação (Mestrado). IG UNICAMP, 2004.

MANZOLLI, IRINEU ARMANDO. Séculos 1920-21: Henrique Lupo fundador do grupo empresarial "Lupo" (1877-2006) 85 anos de sua fundação. Coletânea de documentos organizados a partir do arquivo histórico da empresa Lupo S/A. 2006

\section{MONTEIRO FILHA, DULCE CORREA e} CORREA, ABIDACK - O complexo têxtil. BNDES. 2003.

\section{MORÁBITO, FABIANA JANUSKEIVICTZ.}

Mulher, Trabalho e Família: um estudo de caso entre operárias têxteis.158f. Dissertação (Mestrado em Engenharia de Produção) - Universidade Federal de São Carlos, São Carlos, 1997.
MUNHOZ, ADALBERTO. Uma empresa que tem o pé no chão. Veja no interior-SP. São Paulo, Abril Cultural, v. 23, n. 42, p. 4-7, 1990.

PORTER MICHAEL - A Hora da Estratégia. In: HSM Management, nov.dez.1997.

PROCHNIK, VITOR - "A cadeia têxtil; confecções perante os desafios da Alça e do acordo comercial com a União Européia". Pesquisa MDCI,FINEP UNICAMP. 2003.

SANTOS, LUCIANE DOS. Recontando os pontos do bordado: um estudo de trabalho a domicílio (Araraquara, 1934-1957). $181 \mathrm{f}$. Dissertação (Mestrado em Sociologia). Faculdade de Ciências e Letras da Universidade Estadual Paulista "Júlio de Mesquita Filho".Araraquara. 1997.

SCHEIN, Edgard H. Organizational culture and leadership: a dynamic view. San Francisco: Joney Bass, 1992.

SERRA, JOSÉ - Ciclos e Mudanças Estruturais na Economia Brasileira do pós-guerra. In: BELLUZZO; COUTINHO, R., Desenvolvimento do Capitalismo no Brasil. Campinas: UNICAMP, 1988. v.1.

SILVA, SERGIO. Expansão cafeeira e origens da indústria no Brasil. São Paulo. Alfa Omega, 1976. 